\title{
Diurnal differences in response to oral levodopa
}

\author{
J P Frankel, Z Pirtosek, P A Kempster, M Bovingdon, R Webster, A J Lees, G M Stern
}

\begin{abstract}
Diurnal differences in duration and quality of motor response to levodopa are frequently described by patients. The quality and duration of motor responses were objectively assessed to morning and afternoon oral levodopa doses in five patients with Parkinsonian motor fluctuations who complained of diurnal variation in response to their normal levodopa medication. Results suggest that under controlled conditions which eliminated the effects of diet and overlapping levodopa effects the response to levodopa remained unchanged throughout the day, and that the duration of response could be predicted by plasma levodopa levels.
\end{abstract}

Diurnal variation in response to levodopa medication is commonly reported by patients. This often takes the form of attenuation of response to doses taken later in the day. Patients describe shorter periods of response or failure of response to afternoon and evening doses and motor benefit is marred by a build-up of dyskinetic involuntary movements in the latter half of the day. These phenomena may be due to the effects of diet, particularly protein, interfering with levodopa absorption and transport, loss of "sleep benefit", and changes in dopamine receptor sensitivity either due to natural circadian variations ${ }^{1}$ or as a result of repeated dosing. ${ }^{2}$ A low-protein diet is known to reduce off periods in fluctuating patients; ${ }^{3}$ however, not all are improved and some will still complain of afternoon deterioration after abstaining from a midday meal.

We attempted to analyse the relative contribution of peripheral pharmacokinetic and central pharmacodynamic factors to diurnal variation in response to levodopa. The dura- tion and magnitude of the motor response were compared with plasma levodopa following standard oral doses of levodopa in the early morning; and in the afternoon after taking their usual levodopa medication during the morning.

\section{Patients and methods}

Five patients with Parkinson's disease, two male and three female, agreed to participate in the study after informed consent. Their mean age was 63.4 years (58-69) and duration of levodopa therapy $12 \cdot 2$ years (6-19). All complained of a marked reduction of duration and quality of motor response in the afternoon.

The response to standard oral levodopa $250 \mathrm{mg} /$ carbidopa $25 \mathrm{mg}$ (Sinemet 275) doses were objectively assessed on separate days as follows:

Day 1: Morning levodopa dose. The test dose was administered at 08:00 hours. Anti-Parkinsonian medication was withheld overnight, with a drug free interval of at least ten hours before the test dose. Patients were starved overnight and remained fasting for the duration of the morning motor assessments.

Day 2: Afternoon levodopa dose. Patients were allowed their normal oral levodopa medication until 12:00 hours. The test dose was then delayed until patients had returned to "off" state motor function for 30 minutes. The usual morning levodopa medication for each case is shown in the table. Patients were allowed a normal hospital breakfast but then fasted until the conclusion of the afternoon motor assessments.

Motor assessments were made at 15 minute intervals. Wearing off of motor response was judged to have occurred when performance had declined to, or below, the pre-dose baseline. For the purpose of response duration estimation onset of the motor response was defined as the time point of the upstroke of

Table Brief clinical details, duration of motor responses and plasma levodopa levels in cases studied. Abbreviations for usual anti-Parkinsonian medications: levodopa/beserazide 200/50 mg-M250, 150/37.5 mg-M187, 100/25 mgM125; levodopa/carbidopa 100/25 mg-S+

\begin{tabular}{|c|c|c|c|c|c|c|c|}
\hline \multirow[b]{2}{*}{ Age/Sex } & \multirow{2}{*}{$\begin{array}{l}\text { Duration of levodopa } \\
\text { therapy (years) }\end{array}$} & \multirow{2}{*}{$\begin{array}{l}\text { Usual morning } \\
\text { levodopa regime }\end{array}$} & \multirow{2}{*}{$\begin{array}{l}\text { Times of last } \\
\text { morning levodopa } \\
\text { dose (pm study) }\end{array}$} & \multicolumn{2}{|c|}{$\begin{array}{l}\text { Duration of motor } \\
\text { response (minutes) }\end{array}$} & \multicolumn{2}{|c|}{$\begin{array}{l}\text { Levodopa level } \\
\text { at time of "off" } \\
\text { ( } \mu \mathrm{mol} / \mathrm{l})\end{array}$} \\
\hline & & & & $a m$ & $p m$ & $a m$ & $p m$ \\
\hline $\begin{array}{l}169 / \text { Female } \\
2 \text { 63/Male }\end{array}$ & $\begin{array}{l}19 \\
14\end{array}$ & $\begin{array}{l}M 125 \times 3 \\
M 250 \times 1 \\
M 187 \times 3\end{array}$ & $\begin{array}{l}11.00 \\
12.00\end{array}$ & $\begin{array}{l}180 \\
165\end{array}$ & $\begin{array}{l}225 \\
135\end{array}$ & $\begin{array}{l}3 \cdot 6 \\
2 \cdot 55\end{array}$ & $\begin{array}{l}4 \cdot 4 \\
2 \cdot 25\end{array}$ \\
\hline $\begin{array}{ll}3 & 58 / \text { Male } \\
4 & 63 / \text { Female } \\
5 & 64 / \text { Female }\end{array}$ & $\begin{array}{r}6 \\
13 \\
9\end{array}$ & $\begin{array}{l}\text { M1 } 25 \times 2 \\
S+(\times 2) \times 2 \\
S+\times 3\end{array}$ & $\begin{array}{l}11 \cdot 00 \\
10 \cdot 30 \\
12 \cdot 00\end{array}$ & $\begin{array}{l}360 \\
180 \\
205\end{array}$ & $\begin{array}{l}345 \\
195 \\
195\end{array}$ & $\begin{array}{l}2 \cdot 3 \\
4 \cdot 4 \\
-\end{array}$ & $\begin{array}{l}2 \cdot 3 \\
3 \cdot 6 \\
-\end{array}$ \\
\hline
\end{tabular}


Case 1

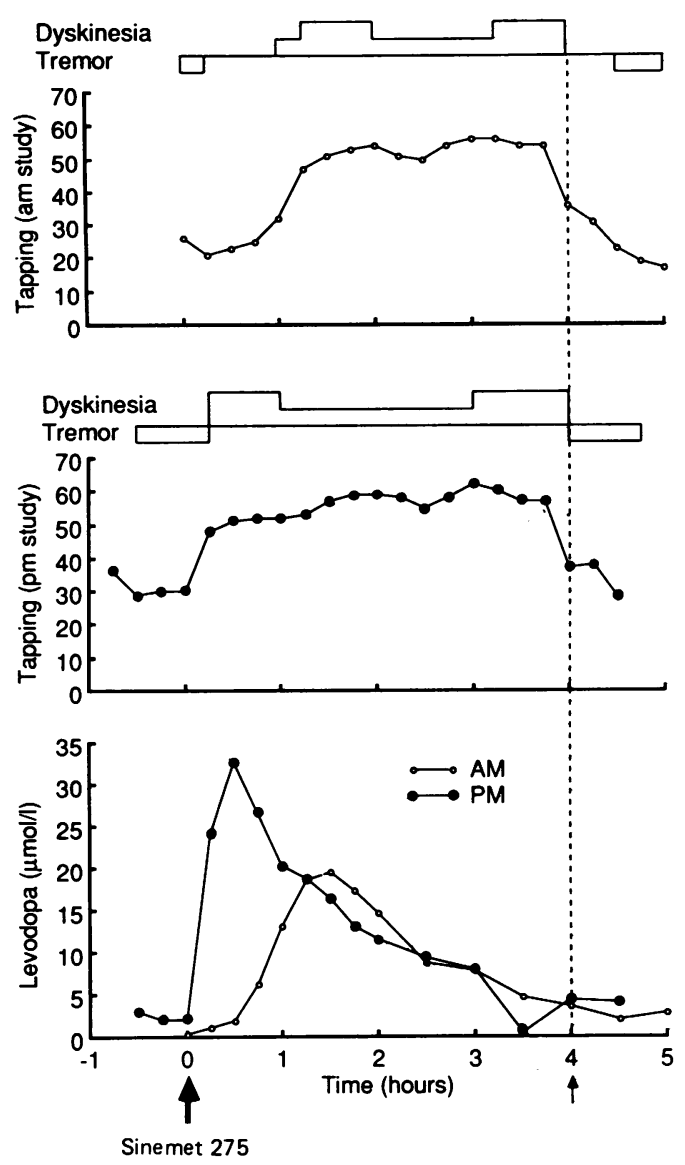

Case 2
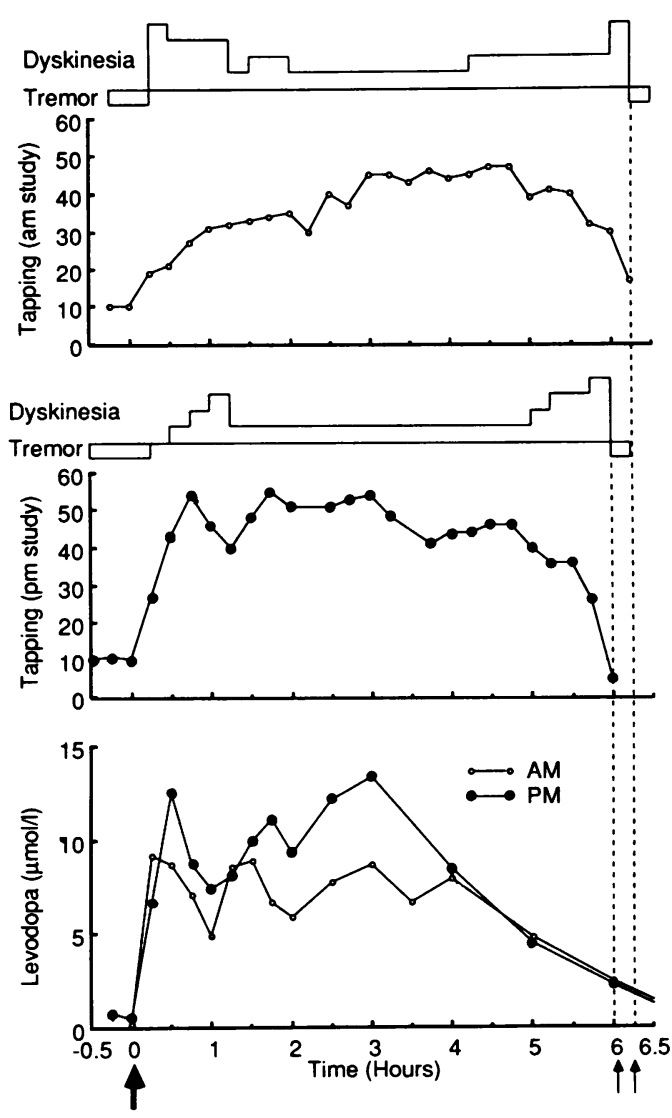

Sinemet 275
Case 3

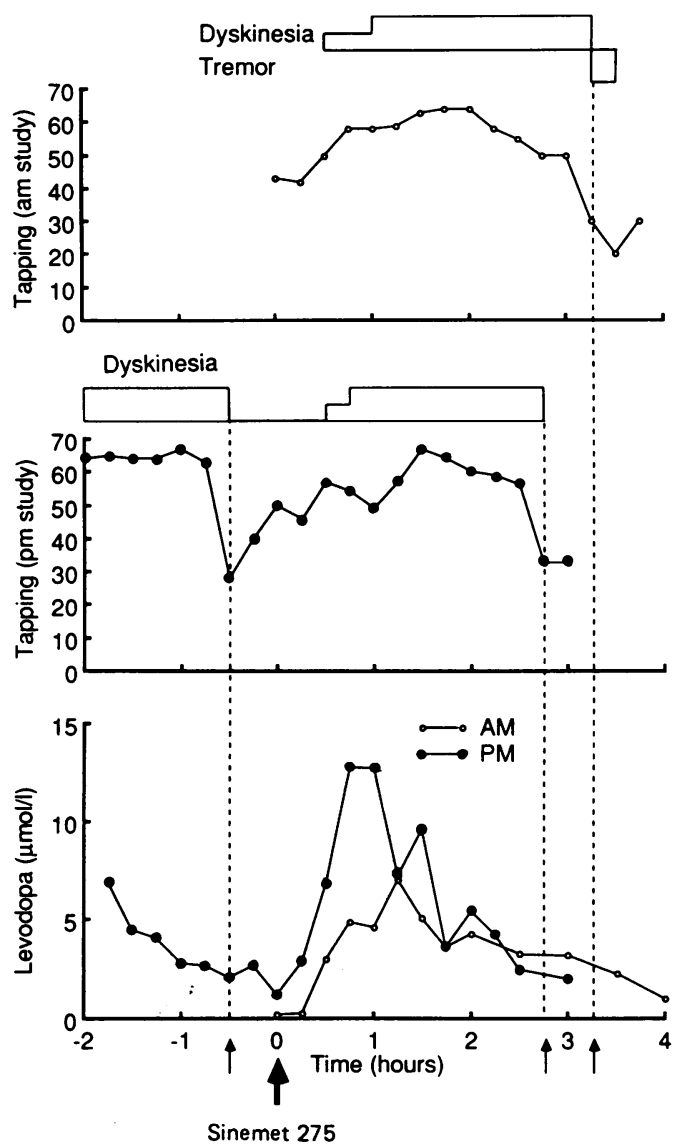

Figures 1-3 Motor response: serial hand tapping and assessment of dyskinesia or tremor, compared with plasma levodopa levels. The motor response is shown for both morning (upper graph) and afternoon studies (lower graph). Levodopa levels at time of wearing off are marked (small arrow).

motor improvement seen on graphical representation of serial motor assessments (figs 1-3). The motor response was evaluated by: 1) a unilateral hand tapping count for 30 seconds on digital counters mounted 20 centimetres apart; 2) timed walking over a 12 metre course; 3) quantitation of tremor or involuntary dyskinetic movement on five point scales.

In four cases blood was drawn at regular intervals throughout the test period, immediately centrifuged and the plasma stored at - 70 degrees centigrade. Aliquots of plasma were assayed for levodopa by HPLC as described previously. ${ }^{4}$ Paired data for duration of motor response and scores for objective motor assessments in the morning and afternoon studies were analysed using Student's $t$ test. A linear correlation coefficient was calculated for motor response duration results.

\section{Results}

Motor response durations to levodopa did not differ significantly in the morning and afternoon (table), with mean times of 218 and 219 minutes respectively. Comparison of morning with afternoon response duration in individual patients revealed a close correlation $(r=0.93$ $\mathrm{p}<0.02)$. 
The relationship between plasma levodopa level and motor function was the same following morning and afternoon doses of levodopa. Plasma levodopa level at the time of wearing off of motor response was similar for morning and afternoon studies in each patient (table), as it was in the one case where the level was also measured at the time of "going off", before the afternoon dose (fig 2). However, the plasma level at the time of wearing off varied almost two-fold across the group as a whole $(2 \cdot 25-4 \cdot 4$ $\mu \mathrm{mol} / \mathrm{l})$.

The degree of motor improvement did not differ significantly between the two studies. No difference in the severity and duration of dyskinetic involuntary movements occurred (figs 1-3).

\section{Discussion}

Most Parkinsonian patients with motor fluctuations complain of an impaired response to levodopa later in the day. The effects of erratic intestinal absorption; levodopa metabolites, such as 3-0-methyldopa, or dietary amino acids interfering with levodopa transport have been implicated. $^{35-7}$ Central mechanisms such as reduced nigro-striatal storage capacity ${ }^{8}$ or changes in post-synaptic receptor sensitivity have also been proposed. ${ }^{9}$ In the case of deteriorating response through the day it may be that there are diurnal changes in sensitivity, possibly an acute change in response to repeated dopaminergic stimulation ${ }^{2}$ or perhaps a circadian rhythm. ${ }^{110}$ Some of these problems may also be due to inhibitory effects of levodopa at low dosage. ${ }^{11}$

The patients chosen for our study all complained of incapacitating loss of responsiveness to levodopa in the afternoon. We compared the response to a standard oral levodopa challenge in the early morning, typically the best time of day, with the effects of the same dose taken in the afternoon, following the usual morning medication. By allowing patients their usual morning levodopa doses we attempted to recreate the situation normally found in the afternoon. We were not able to show any diurnal change in magnitude or duration of motor response under these conditions. The relationship between plasma levodopa level and timing of wearing off of motor response was the same for morning and afternoon doses. No evidence for a diurnal alteration of striatal dopamine receptor sensitivity was found, which should have been reflected by a change in plasma levodopa level threshold for onset and wearing off of motor response. Patients appear to have the capacity to respond to afternoon oral doses of levodopa when optimum drug absorption is ensured. Gancher and Nutt showed similar diurnal equivalence of motor responses to subcutaneous apomorphine, ${ }^{12}$ and our own experience in the practical treatment of patients with Parkinsonian motor oscillations using subcutaneous apomorphine is that patients retain responsiveness to apomorphine boluses during "off" periods irrespective of the time of day. ${ }^{13}$

The study was performed under controlled circumstances in hospital and may not have reproduced the adverse effects of fatigue ${ }^{14}$ on responsiveness to levodopa medication late in the day. We did not allow our patients to take a midday meal, thereby avoiding the complicating effects of diet. To assess afternoon motor response duration patients were allowed to go "off" before the test dose was given; and this may have allowed some recovery from the possible effects of earlier cycles of phasic dopamine receptor stimulation on receptor sensitivity.

These results suggest that the motor response to levodopa remains unchanged throughout the day under the controlled conditions employed here. Further studies are required to determine the explanation for the frequently reported reduction in duration and quality of motor response to levodopa doses later in the day.

JPF and PAK were supported by the Kate Stillman Research Fellowship. We thank the Medical Illustration Department Middlesex Hospital, for assistance with preparation of the figures.

1 Lemmer B, Berger T. Diurnal rhythm in the central dopamine turnover in the rat. Naunyn Schmiedebergs Arch Pharmacol 1978;303:257-61.

2 Trulson ME, Crisp T. Behavioral and neurochemical effects of apomorphine in the cat. Eur J Pharmacol 1982;80: 295-309.

3 Tsui JK, Ross S, Poulin K, Douglas J, Postnikoff D, Calne $S$, Woodward W, Calne DB. The effect of dietary protein on the efficacy of L-dopa: a double blind study. Neurology 1989;39:549-52.

4 Kempster PA, Frankel JP, Bovingdon M, Webster A, Lees AJ, Stern GM. Levodopa peripheral pharmacokinetics and duration of motor response in Parkinson's
Neurol Neurosurg Psychiatry 1989;52:718-23.

5 Kurlan R. Dietary therapy for motor fluctuations in Parkinson's disease. Arch Neurol 1987;44:1119-21.

6 Wade LA, Katzman A. 3-0-methyldopa uptake and inhibition of levodopa at the blood-brain barrier. Life Sci 1975;17:131-6.

7 Nutt JG, Woodward WR, Hammerstad JP, Carter JH, Anderson JL. The "on-off" phenomenon in Parkinson's disease: relation to levodopa absorption and transport. $N$ Engl J Med 1984;310:483-8.

8 Marsden CD. On-off phenomenon. In Rinne UK, Klingler M, Stamm S, eds. Parkinson's disease: current progress,
problems and management. Amsterdam: Elsevier/North Holland Publishing, 1980:241-54.

9 Mouradian MM, Juncos JL, Fabbrini G, Chase TH. Motor fluctuations in Parkinson's disease: pathogenic and fluctuations in Parkinson's disease: pathoge
therapeutic studics. Ann Neurol 1987;22:475-9.

10 Bruinink A, Lichtensteiger W, Schlumpf M. Ontogeny of diurnal rhythms of central dopamine, serotonin and spirodecanone binding sites and of motor activity in the spirodecanone binding sites
rat. Life Sci 1983;33:31-8.

11 Nutt JG, Gancher ST, Woodward WR. Does an inhibitory action of levodopa contribute to motor fluctuations? Neurology 1988;38:1553-7.

12 Gancher ST, Nutt JG. Diurnal responsiveness to apomorphine. Neurology 1987;37:1250-3.

13 Stibe CMH, Lees AJ, Kempster PA, Stern GM. Subcutaneous apomorphine in Parkinsonian on-off oscillations. Lancet 1988;i:403-6.

14 Marsden CD, Parkes JD, Quinn N. Fluctuation of disability in Parkinson's disease-clinical aspects. In Marsden CD, Fahn S, eds. Movement Disorders. London: Butterworth Scientific, 1982:96-122. 